and less likely to receive ETA, consistent with the superior efficacy of monoclonal TNFi for these conditions. The presence or absence of EAMS did not influence the use of CZP, although small sample size might explain the lack of associations. Future work will determine whether EAMS influence TNFi survival, or effectiveness, and whether this varies between agents.

Acknowledgement: British Society of Rheumatology

Disclosure of Interests: Mohammad H. Derakhshan: None declared, Linda Dean: None declared, Gareth T. Jones Grant/research support from: Have received research grants (not current) from Abbvie and Pfizer.

Have received research grants (not current) from the British Society for Rheumatology, who received the funds from Abbive, Pfizer and UCB.

Have received research grant (current) from the British Society for Rheumatology, who received the funds from Celgene., Gary Macfarlane Grant/research support from: Have received research grants (not current) from Abbvie and Pfizer. Have received research grants (not current) from the British Society for Rheumatology, who received the funds from Abbive, Pfizer and UCB.

Have received research grant (current) from the British Society for Rheumatology, who received the funds from Celgene., Stefan Siebert Grant/research support from: AbbVie, Novartis, Pfizer, Janssen, BMS, Celgene, UCB, and Boehringer Ingelheim, Consultant for: AbbVie, UCB, Pfizer, Janssen, Boehringer Ingelheim, Celgene, and Novartis, Speakers bureau: AbbVie, UCB, Pfizer, Janssen, Boehringer Ingelheim, Celgene, and Novartis, Karl Gaffney Grant/research support from: Abbvie, Pfizer, Consultant for: Abbvie, Lilly, Novartis, UCB, Speakers bureau: Abbvie, Biogen, Gilead, Lilly, Novartis, UCB

DOI: 10.1136/annrheumdis-2019-eular.3010

\section{OP0234 \\ EFFICACY AND SAFETY OF BRODALUMAB, AN ANTI- INTERLEUKIN-17 RECEPTOR A MONOCLONAL ANTIBODY, IN PATIENTS WITH AXIAL SPONDYLOARTHRITIS: A 16 WEEK RESULTS OF A PHASE 3, MULTICENTER, RANDOMIZED, DOUBLE- BLIND, PLACEBO-CONTROLLED STUDY}

James Cheng-Chung Wei ${ }^{1}$, Tae-Hwan $\mathrm{Kim}^{2}{ }^{2}$, Mitsumasa Kishimoto ${ }^{3}$, Takuya Morishige ${ }^{4}$, Naoki Ogusu ${ }^{4}$, Shigeto Kobayashi ${ }^{5} .{ }^{1}$ Chung Shan Medical University Hospital, Taichung, Taiwan, Republic of China; ${ }^{2}$ Hanyang University Seoul Hospital, Seoul, Korea, Rep. of (South Korea); ${ }^{3}$ St. Luka's International Hospital, Tokyo, Japan; ${ }^{4}$ Kyowa Hakko Kirin Co., Ltd., Tokyo, Japan; ${ }^{5}$ Juntendo University Koshigaya Hospital, Tokyo, Japan

Background: It is known that clinical features and pathophysiological pathways of ankylosing spondylitis (AS) and non-radiographic axial spondyloarthritis (nr-axSpA) have similarities. Recent reports suggest that IL-17 signaling pathway may be involved in development of axial spondyloarthritis $(\operatorname{axSpA})$. Here we reported the confirmatory phase 3 trial of brodalumab, a human anti-interleukin-17 receptor $A$ monoclonal antibody, in patients with axSpA (4827-006 Study, NCT02985983).

Objectives: To evaluate the efficacy and safety of brodalumab in axSpA (including $\mathrm{AS}$ and $\mathrm{nr}-\mathrm{axSpA}$ ) patients at week 16 .

Methods: In this phase 3, multicenter, randomized, double-blind, placebo-controlled study conducted in Japan, South Korea and Taiwan, eligible axSpA patients were randomized 1:1 to brodalumab subcutaneously (s.c.) $210 \mathrm{mg}$ or placebo at baseline, weeks 1 and 2, every 2 weeks thereafter. At week 16, all subjects entered an open label extension phase and received brodalumab $210 \mathrm{mg} \mathrm{s}$. c. Q2W. ASAS 40 (Assessment of SpondyloArthritis international Society) response rate at week 16 was the primary endpoint. Secondary outcomes and safety profiles were also assessed.

Results: A total of 159 patients were randomized, and 77/80 patients in brodalu mab arm and 69/79 patients in placebo arm were completed the 16 weeks' doubleblind phase study. The ASAS 40 response rate at week 16 was significantly higher in brodalumab group $(35 / 80,43.8 \%, p=0.018)$ compared to placebo group $(19 / 79$, $24.1 \%)$. Other disease activity parameters demonstrated trend to improvement in therapeutic arm (Table). Brodalumab $210 \mathrm{mg}$ had good safety profile. Most commonly reported adverse event was nasopharyngitis observed in both brodalumab $(11.1 \%)$ and placebo $(10.3 \%)$ arms. AE rates including SAE rates were comparable between groups. No suicidal ideation or behavior were observed.

Conclusion: Brodalumab s.c. $210 \mathrm{mg}$ Q2W treatment was effective and tolerable in axSpA patients in this 16 week phase 3 clinical trial. Based on the ongoing trial results, brodalumab could be considered as a future therapeutic option for patients with axSpA.
Table 1. Summary of efficacy result at Week 16 (FAS)

\begin{tabular}{|c|c|c|}
\hline \multirow[t]{2}{*}{ Efficacy End Points } & \multicolumn{2}{|c|}{ axSpA $(\mathrm{N}=159)$} \\
\hline & $\begin{array}{l}\text { Placebo } \\
(\mathrm{N}=79)\end{array}$ & $\begin{array}{c}210 \mathrm{mg} \\
\text { Brodalumab } \\
(\mathrm{N}=80)\end{array}$ \\
\hline ASAS 40 Response at Week 16 (NRI), n (\%) & $19(24.1)$ & $\begin{array}{l}35(43.8 \\
\mathrm{p}=0.018)\end{array}$ \\
\hline ASAS 20 Response at Week 16 (NRI), n (\%) & $33(41.8)$ & $54(67.5)$ \\
\hline $\begin{array}{l}\text { ASDAS-CRP change from baseline at Week } 16 \\
\text { (BOCF), LS mean }\end{array}$ & -0.672 & -1.127 \\
\hline BASDAI change from baseline at Week 16, Mean & -2.4 & -2.9 \\
\hline BASFI change from baseline at Week 16, Mean & -0.7 & -1.1 \\
\hline
\end{tabular}

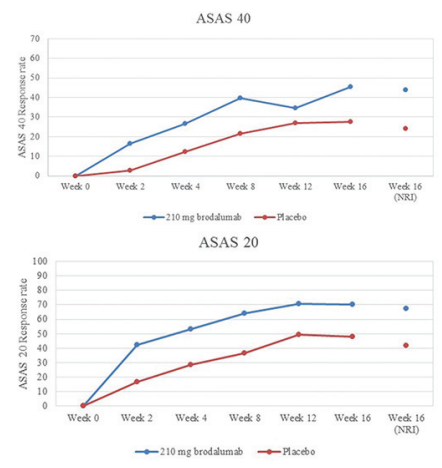

Figure. ASAS 20/40 response rate

Disclosure of Interests: James Cheng-Chung Wei Grant/research support from: Abbvie, BMS, Celgene, Janssen, Novartis, Pfizer, and UCB pharma, Consultant for: TSH Taiwan, Speakers bureau: Janssen, Novartis, Pfizer and TSH Tae-hwan Kim: None declared, Mitsumasa Kishimoto Consultant for: Kyowa Hakko Kirin Co., Ltd., Takuya Morishige Employee of: Kyowa Hakko Kirin Co., Ltd., Naoki Ogusu Employee of: Kyowa Hakko Kirin Co., Ltd., Shigeto Kobayashi Grant/research support from: Chugai pharmaceutical Co., Ltd., Consultant for: Kyowa Hakko Kirin Co., Ltd., Eli Lilly, Novartis.

DOI: 10.1136/annrheumdis-2019-eular.6888

\begin{tabular}{|l|l}
\hline OP0235 & SECUKINUMAB IMPROVES AXIAL MANIFESTATIONS \\
IN PATIENTS WITH PSORIATIC ARTHRITIS AND \\
INADEQUATE RESPONSE TO NSAIDS: PRIMARY \\
ANALYSIS OF THE MAXIMISE TRIAL
\end{tabular}

Xenofon Baraliakos ${ }^{1}$, Laura C Coates ${ }^{2}$, Laure Gossec ${ }^{3}$, Sławomir Jeka ${ }^{4}$, Antonio Mera Varela ${ }^{5}$, Barbara Schulz ${ }^{6}$, Michael Rissler ${ }^{6}$, Ayan Das Gupta ${ }^{7}$

Chiara Perella ${ }^{6}$, Effie Pournara $6 .{ }^{1}$ Rheumazentrum Ruhrgebiet, Ruhr University Bochum, Germany, Herne, Germany, ${ }^{2}$ University of Oxford, Oxford, United Kingdom; ${ }^{3}$ Sorbonne Universite, Hopital Pitie-Salpetriere, Paris, France; ${ }^{4} 2 n d$ University Hospital, CM UMK, Bydgoszcz, Poland; ${ }^{5}$ Santiago University Clinical Hospital, Santiago de Compostela, Spain; ${ }^{6}$ Novartis Pharma AG, Basel, Switzerland; ${ }^{7}$ Novartis Healthcare Pvt. Ltd, Hyderabad, India

Background: Secukinumab (SEC) has provided significant and sustained improvement in the signs and symptoms of active psoriatic arthritis (PsA) and ankylosing spondylitis ${ }^{1}$. Evidence on the efficacy of biologics in the treatment of PsA patients (pts) with axial manifestations affecting $30-70 \%$ of PsA pts is limited $^{2}$, particularly as validated classification criteria for this subtype of PsA are not yet available; an effort to develop criteria is being undertaken by ASAS/GRAPPA. MAXIMISE is an ongoing study evaluating the efficacy and safety of secukinumab 300 or $150 \mathrm{mg}$ in managing axial manifestations in PsA pts

Objectives: To report the primary analysis results at Week (Wk) 12 from MAXIMISE (NCT02721966) trial

Methods: This phase 3b, double blind, placebo (PBO)-controlled, multicentre 52wk trial included 498 pts (aged $\geq 18$ years) with PsA (CASPAR criteria), clinician- 
diagnosed axial involvements, spinal pain VAS >40/100 and BASDAI >4 despite trial of at least two NSAIDs. Pts were randomised to subcutaneous (SC) SEC (300/150 mg) or PBO weekly for 4 wks and every 4 wks thereafter. At Wk 12, PBO pts were re-randomised to SC SEC 300/150 mg. The primary endpoint was proportion of pts achieving ASAS20 response with SEC $300 \mathrm{mg}$ at Wk 12. The key secondary endpoint was ASAS20 response with SEC 150 $\mathrm{mg}$ at Wk 12 after superiority of $300 \mathrm{mg}$ was established. Analyses used multiple imputation

Results: Demographic and baseline (BL) disease characteristics were comparable across groups (Table). Primary and key secondary endpoints were met; ASAS20 response rates at Wk 12 were $63.1 \%$ (SEC $300 \mathrm{mg} ; \mathrm{P}<0.0001$ ) and $66.3 \%$ (150 mg; $\mathrm{P}<0.0001$ ) vs 31.3\% (PBO; Figure). ASAS20 responses in pts using concomitant MTX were 65.1\% [300 mg], 67.3\% [150 mg] vs 33.9\% [PBO] and corresponding values in No MTX group were $60.5 \%, 64.4 \%$ vs $27.1 \%$. The safety profile was similar across groups through Wk 12

Conclusion: MAXIMISE is the first randomised controlled trial evaluating the efficacy of a biologic in the management of the axial manifestations of PSA. SEC 300 and $150 \mathrm{mg}$ provided rapid and significant improvement in ASAS20 responses through Wk 12 in PsA pts with axial manifestations and inadequate responses to NSAIDs

\section{REFERENCES:}

[1] Lubrano E and Perrotta FM. Ther Clin Risk Manag. 2016;12:1587-92 [2] Feld J, et al. Rheum Rev.2018;14:363

\begin{tabular}{|c|c|c|c|}
\hline \multicolumn{4}{|l|}{ Demographics/BL Characteristics } \\
\hline Mean (SD) unless specified & $\begin{array}{c}\text { SEC } \\
300 \mathrm{mg} \mathrm{SC} \\
(\mathrm{N}=167)\end{array}$ & $\begin{array}{c}\text { SEC } \\
150 \mathrm{mg} \mathrm{SC} \\
(\mathrm{N}=165)\end{array}$ & $\begin{array}{c}\text { PBO } \\
(\mathrm{N}=166)\end{array}$ \\
\hline Age (yrs) & $46.2(12.3)$ & $46.9(11.5)$ & $46.6(11.5)$ \\
\hline Male, $\mathrm{n}(\%)$ & $77(46.1)$ & $81(49.1)$ & $88(53.0)$ \\
\hline Evidence of current psoriasis, $n(\%)$ & $152(91.0)$ & $147(89.1)$ & $153(92.2)$ \\
\hline Time since first axial symptoms (yrs) & $6.8(7.7)$ & $7.4(7.6)$ & $7.7(9.5)$ \\
\hline $\begin{array}{l}\text { Total back pain score, VAS } \\
\text { Inflammatory back pain parameters, } \mathrm{n}(\%)\end{array}$ & $72.5(13.8)$ & $73.6(15.3)$ & $74.0(13.7)$ \\
\hline Onset of back pain is insidious & $150(8$ & $147(89.1)$ & $152(91.6)$ \\
\hline oving with exercise & $148(8$ & $139(84.2)$ & $146(88.0)$ \\
\hline rsening with rest & $152(91.0)$ & $151(91.5)$ & $157(94.6)$ \\
\hline Night pain with improvement upon ge & $147(88.0)$ & $147(89.1)$ & $143(86.1)$ \\
\hline Awakening due to back pain in $2^{\text {nd }}$ half of night & $143(85.6)$ & $145(87.9)$ & $137(82.5)$ \\
\hline Alternating buttock pain & $102(61.1)$ & $98(59.4)$ & $101(60.8)$ \\
\hline Back pain improved after NSAID intake in past & $136(81.4)$ & $134(81.2)$ & $138(83.1)$ \\
\hline BASDAI & $7.3(1.2)$ & $7.2(1.4)$ & $7.3(1.2)$ \\
\hline HLA-B27 positive, n/M (\%) & $31 / 85(36.5)$ & $24 / 82(29.3)$ & $26 / 74(35.1$ \\
\hline
\end{tabular}

M, number of pts with available HLA-B27 status

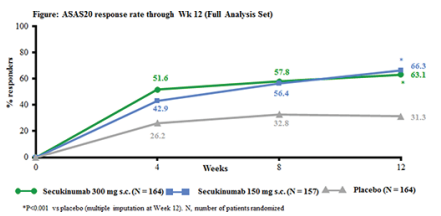

Disclosure of Interests: Xenofon Baraliakos Grant/research support from: AbbVie, Boehringer Ingelheim, Bristol-Myers Squibb, Celgene, Centocor, Chugai, Janssen, MSD, Novartis, Pfizer Inc, Roche and UCB, Grant/research support from: AbbVie, Pfizer, Merck Sharp \& Dohme, UCB Pharma, Novartis, Consultant for: AbbVie, Bristol-Myers Squibb, Boehringer Ingelheim, Celgene, Chugai, Janssen Biologics, Novartis, Pfizer, UCB Pharma, Galapagos, Speakers bureau: AbbVie, Chugai, Janssen, Novartis, Pfizer, UCB Pharma, Laura C Coates Grant/research support from: AbbVie, Celgene, Lilly, Novartis and Pfizer, Consultant for: AbbVie, Amgen, BMS, Celgene, Galapagos, Gilead Sciences Inc., Janssen, Lilly, Novartis, Pfizer, Prothena Corp and UCB, Laure Gossec Grant/research support from: AbbVie, BMS, Celgene, Janssen, Lilly, MSD, Novartis-Sandoz, Pfizer, Sanofi, and UCB, Consultant for: AbbVie, Biogen, BMS, Celgene, Janssen, Lilly, MSD, Nordic Pharma, Novartis-Sandoz, Pfizer, Roche, Sanofi, and UCB, Consultant for: $L$ Gossec has received honoraria from Celgene as investigator for this study, Sławomir Jeka: None declared, ANTONIO MERA VARELA: None declared, Barbara Schulz Employee of: Novartis, Michael Rissler Employee of: Novartis, Ayan Das Gupta Employee of: Novartis, Chiara Perella Employee of: Novartis, Effie Pournara Shareholder of: Novartis, Employee of: Novartis

DOI: 10.1136/annrheumdis-2019-eular.2932

\section{OP0236 \\ SIMILAR ONE-YEAR TREATMENT RETENTION OF ORIGINATOR AND BIOSIMILAR ETANERCEPT. RESULTS OF A NORDIC COLLABORATION INCLUDING 1015 PATIENTS WITH SPONDYLOARTHRITIS}

Bente Glintborg ${ }^{1}$, Ulf Lindström² ${ }^{2}$ Daniela DI Giuseppe ${ }^{3}$, Johan Askling ${ }^{3}$, Dan Nordström ${ }^{4}$, Sella Aarrestad Provan ${ }^{5}$, Björn Gudbjornsson ${ }^{6}$, Merete

L. Hetland ${ }^{1}$, Kalle Aaltonen ${ }^{7}$, Arni Jon Geirsson ${ }^{6}$, Niels Steen Krogh ${ }^{1}$, Lennart T. H. Jacobsson'. ${ }^{1}$ DANBIO, Copenhagen, Denmark; ${ }^{2}$ Sahlgrenska Academy, University of Gothenburg, Gothenburg, Sweden; ${ }^{3}$ Karolinska Institutet, Stockholm, Sweden; ${ }^{4}$ ROB-FIN, Helsinki University and University Hospital, Helsinki, Finland; ${ }^{5}$ Diakonhjemmet Hospital, Oslo, Norway, ${ }^{6}$ ICEBIO and University of Iceland, Reykjavik, Iceland; ${ }^{7}$ Ministry of Social Affairs and Health, Helsinki, Finland

Background: The marketing approval of the etanercept biosimilar SB4 was based on phase III studies on patients with rheumatoid arthritis, but extended to all etanercept indications. Currently, no randomized controlled trials have compared etanercept originator (ETN) with SB4 in patients with spondyloarthritis (SpA). However, the uptake of etanercept biosimilars in the treatment of SpA has been exponential in the Nordic countries, with marked differences across the countries [1].

Objectives: To compare the one-year treatment retention in bio-naïve patients with SpA treated with ETN versus SB4. Furthermore, to explore baseline characteristics in the two patient groups.

Methods: Observational cohort study. Patients with SpA (ankylosing spondylitis (AS), non-radiographic axial SpA (nrax-SpA) or uSpA)), starting etanercept as their first ever TNFi Jan 2014 through Jun 2017 were identified in biologics registers in the five Nordic countries. Baseline characteristics were retrieved from each biological register and comorbidity data through linkage to national registers. The country-specific data were then pooled for further analysis. Comparisons of treatment retention between ETN and SB4 were assessed through survival probability curves and one-year retention rates.

Results: In total, 1015 patients were included, whereof $49 \%$ started ETN and $51 \%$ SB4. Baseline characteristics were similar in the two patient groups (Table 1).

Table 1. Baseline characteristics of etanercept treated SpA patients

\begin{tabular}{lcc}
\hline & ETN $(\mathrm{N}=493)$ & $\mathrm{SB} 4(\mathrm{~N}=522)$ \\
\hline Age, years & $41(14)$ & $41(14)$ \\
Disease duration, years & $12(12)$ & $11(12)$ \\
Sex, men,\% & 48 & 50 \\
AS,\% & 41 & 38 \\
nrax-SpA or uSpA,\% & 59 & 62 \\
Psoriasis ${ }^{*}, \%$ & 7 & 5 \\
Inflammatory bowel disease ${ }^{*} \%$ & 2 & 2 \\
CRP, mg/L & $11(18)$ & $10(15)$ \\
VAS-pain, mm & $59(24)$ & $59(22)$ \\
ASDAS & $3.05(0.90)$ & $2.98(0.94)$ \\
BASDAI, mm & $5.4(2.0)$ & $5.4(1.9)$ \\
BASFI & $4.1(2.4)$ & $4.1(2.5)$ \\
Concomitant csDMARD,\% & 29 & 22 \\
\hline Numbers are means $(\mathrm{stan}$ ) & 29 &
\end{tabular}

Numbers are means (standard deviations) unless otherwise stated

ETN=etanercept originator; SB4= etanercept biosimilar

*) comorbidities only available from Sweden, Denmark and Finland.

csDMARD = conventional synthetic Disease Modifying anti-Rheumatic Drugs.

One-year survival probability curves were similar for ETN compared to SB4 (Fig ure 1), and the proportions of patients remaining on drug after one year were comparable: ETN 66\% (95\%Cl: $61-70 \%)$ and SB4 73\% (95\%Cl: $68-78 \%)$. Further confounder-adjusted analyses are planned and will be presented at the conference.

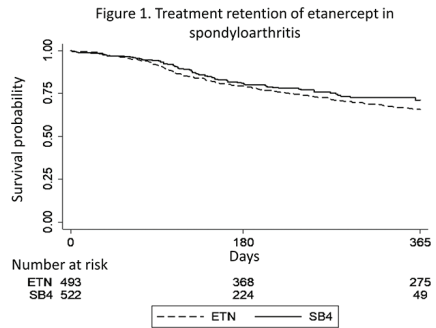

Conclusion: In this observational study of 1015 patients with SpA from five Nordic countries, biologics-naïve patients starting treatment with originator versus biosimilar etanercept had similar baseline characteristics and similar one-year treatment retention rates, suggesting similar effectiveness and tolerability of the two drugs. 